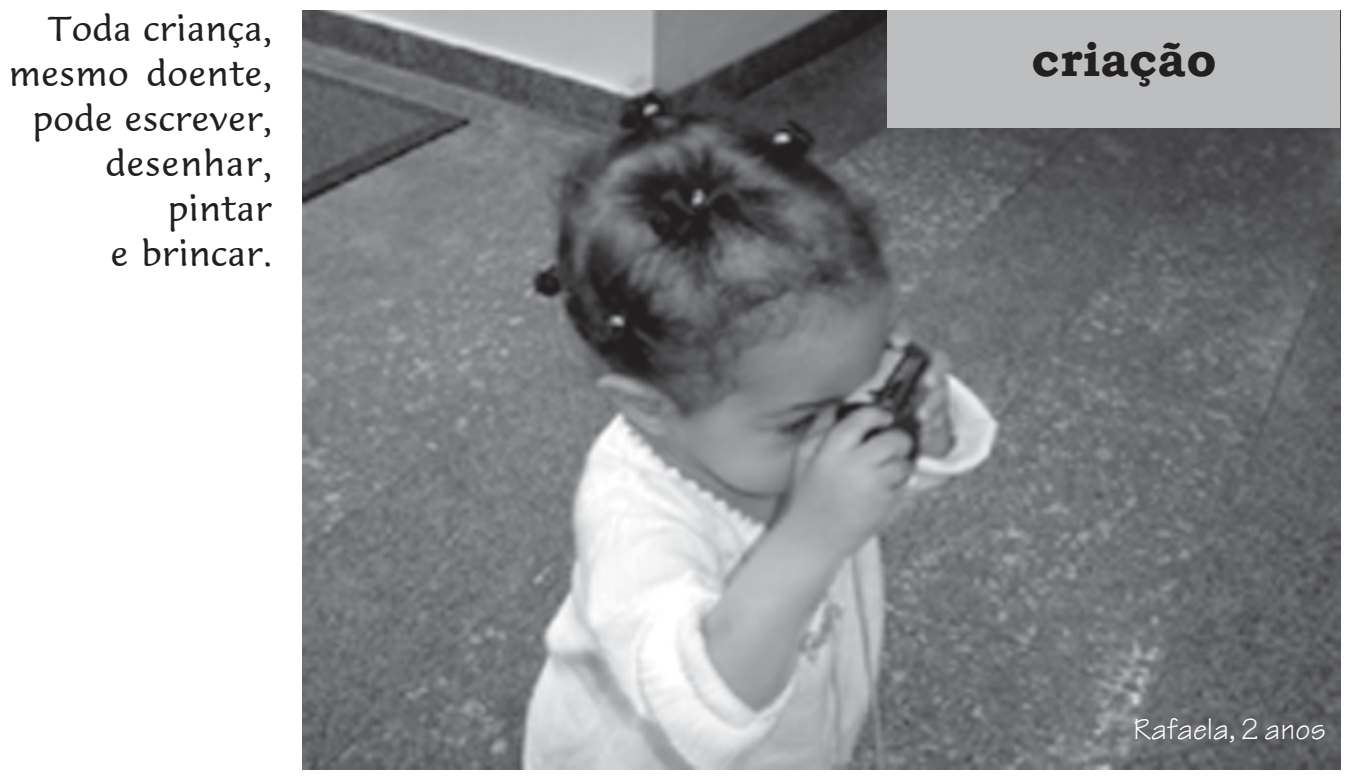

\title{
Exposição de fotografias: o hospital pelo olhar da criança
}

Photographic exhibition: the hospital, as seen through the eyes of a child

Aide Mitie Kudo,

terapeuta ocupacional, supervisora de Seção

Hospitalar, Instituto da

Criança, Hospital das

Clínicas, Faculdade de

Medicina, Universidade de

São Paulo, SP.

<aidemk@icr.hcnet.usp.br>

Priscila Bagio Maria,

terapeuta ocupacional,

Instituto da Criança,

Hospital das Clínicas,

Faculdade de Medicina,

Universidade de São Paulo.

<pbagio@icr.hcnet.usp.br>

Instituto da Criança, Hospital das Clínicas, FMUSP

Av. Dr. Enéas Carvalho de Aguiar, 647

São Paulo, SP

05.403-900
Visando resgatar uma prática de saúde baseada no respeito às necessidades individuais da criança, o Serviço de Terapia Ocupacional do Instituto da Criança do Hospital das Clínicas da Faculdade de Medicina da Universidade de São Paulo (HC/FMUSP) abriu espaço para atividades expressivas e lúdicas comuns na infância.

Com o intuito de divulgar as habilidades $e$ criatividade dos pequenos pacientes surgiu o projeto “Exposição Talentos Mirins". Em sua primeira edição, a iniciativa trabalhou com desenhos e gravuras das crianças. Em dezembro de 2005, ganhou uma nova versão, com a realização de um concurso de fotografias tiradas pelas crianças internadas ou em tratamento no Instituto da Criança ( $\mathrm{ICr}$ ) e Instituto de Tratamento do

Câncer Infantil (ITACI), evento que contou com a parceria da Unidade de Dor e Medicina Paliativa do ICr.

Durante duas semanas, os pacientes, maiores de dois anos, percorreram diversas áreas do hospital munidos de máquinas fotográficas e registrando cenas. Pôde-se, então, conhecer a percepção da criança sobre o hospital e seu ponto de vista sobre os processos de tratamento. A experiência foi inovadora para as crianças, que experimentaram uma atividade diferente no cotidiano hospitalar. 

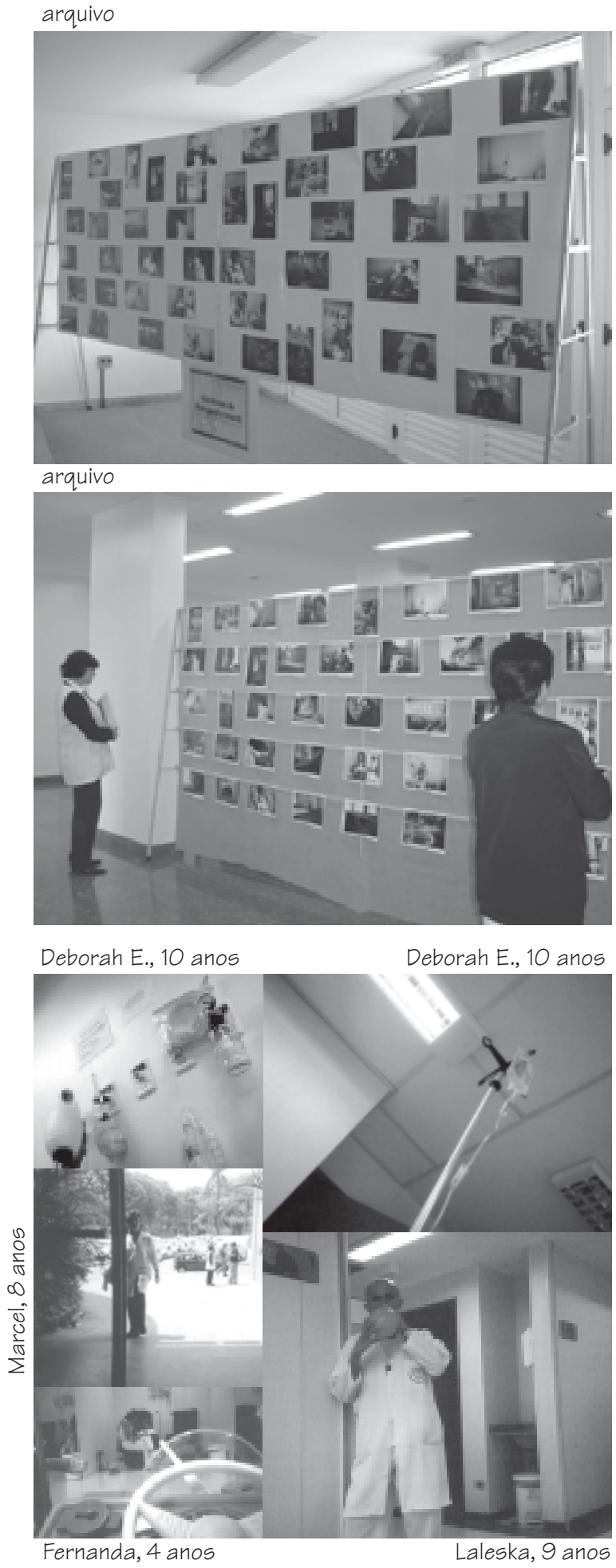

Foram organizadas duas exposições em que profissionais da instituição puderam apreciar e refletir sobre a produção das crianças, que mostrou detalhes imperceptíveis e ângulos diferentes dos da visão do adulto.

Os visitantes votaram nas melhores imagens, compondo um calendário, parte do Programa Plantão Contra a Dor - "Quando a dor rima com o amor pelos olhos da criança". 
CRIAÇÃO

Das mais de mil fotos analisadas, a comissão julgadora escolheu 46, que mais caracterizavam a percepção da criança do ambiente hospitalar.

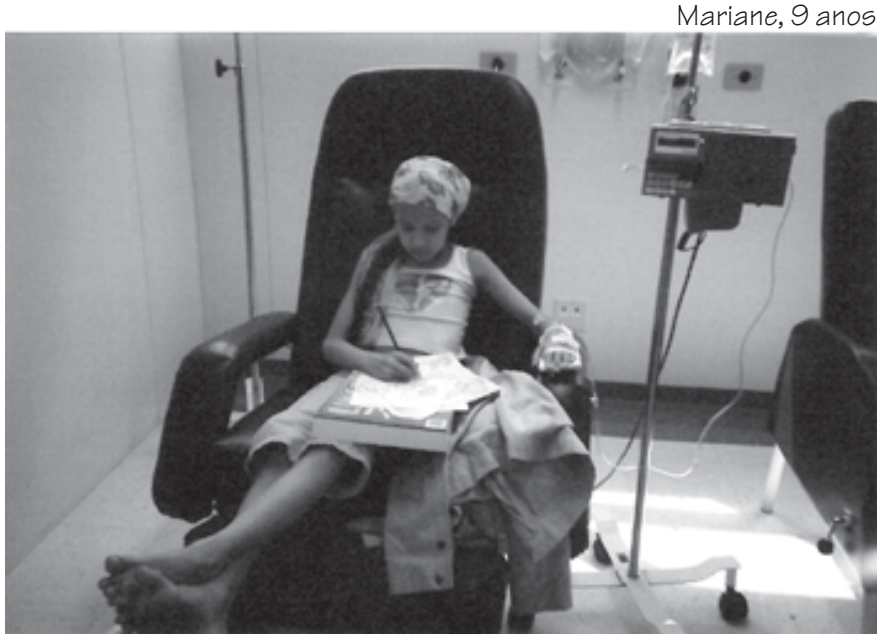

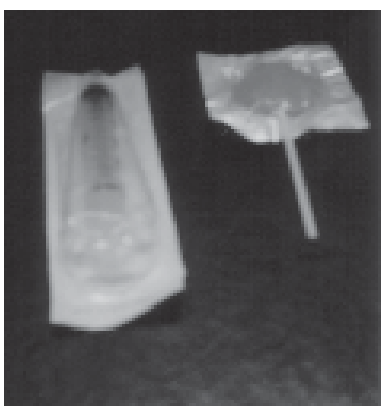

Gabriel, 9 anos

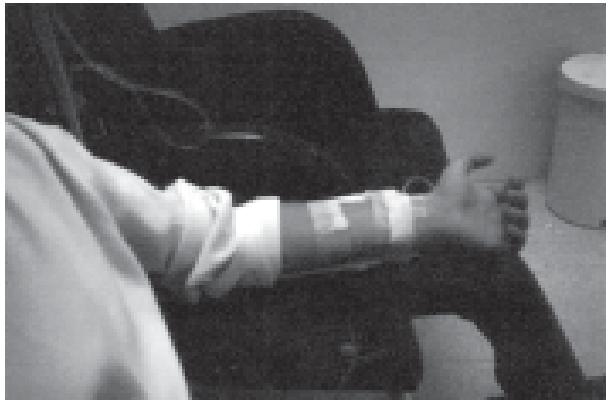

Michael, 7 anos

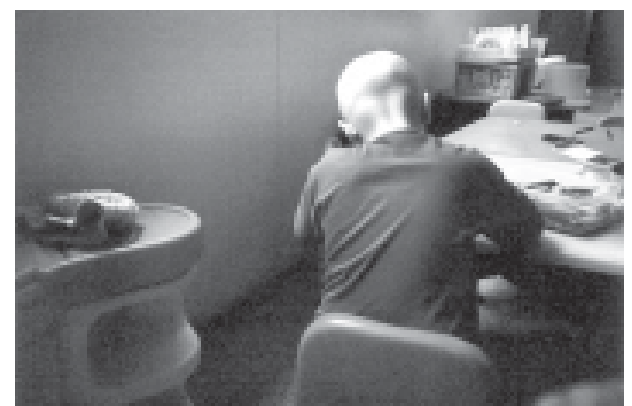

Anthony, 4 anos

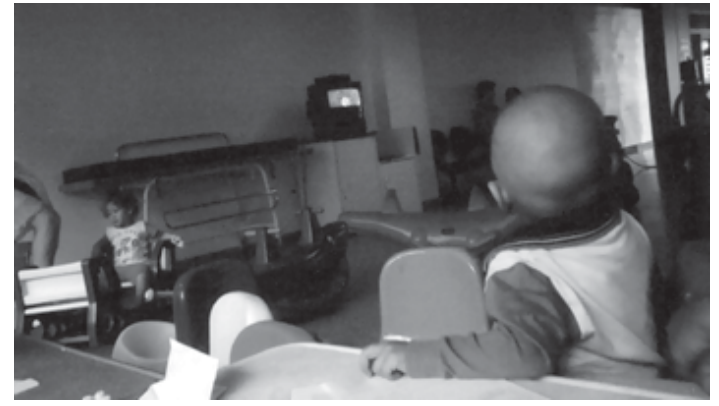

Marcos Vinícius, 7 anos

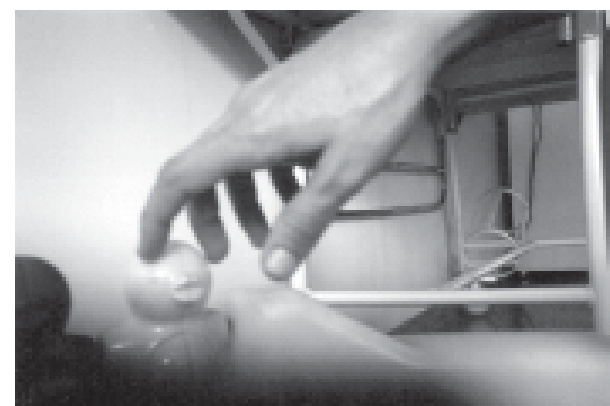

Ariane, 2 anos

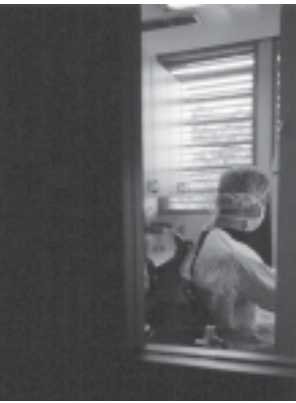

Juliana, 6 anos 
CRIAÇÃO

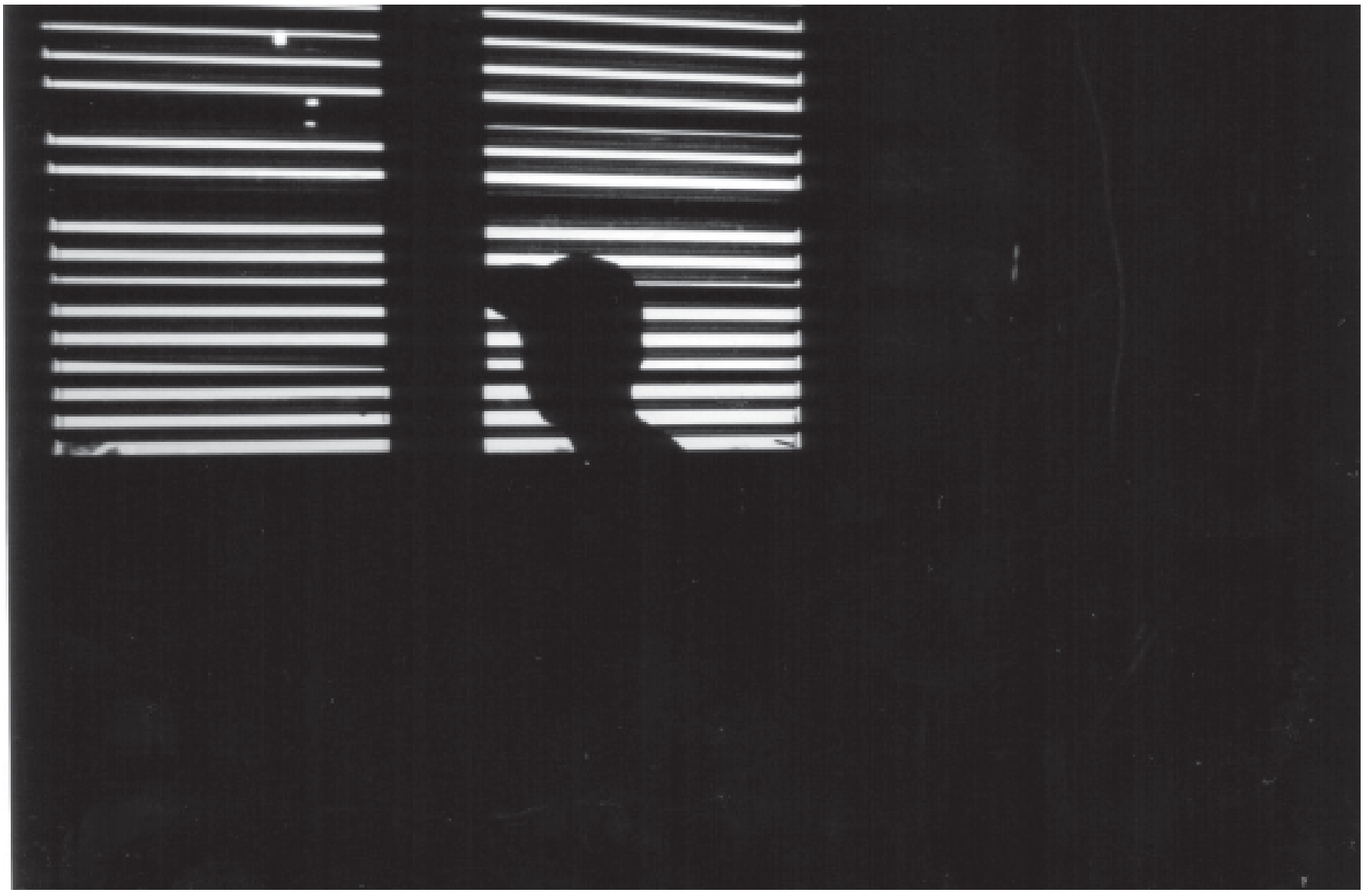

Jaqueline, 11 anos

184 Interface - Comunic, Saúde, Educ, v.11, n.21, p.181-4, jan/abr 2007 